\title{
NOVAS DIREÇÕES NA ECONOMIA DO TRABALHO - UMA REVISÃO CRÍTICA DA LITERATURA BRASILEIRA NO PERÍODO 2007-2016
}

\begin{abstract}
Rodrigo Siqueira Rodriguez*
RESUMO

Alexandre Novaes Mejdalani*

Este artigo apresenta uma revisão da literatura do período 2007-2016 no campo de estudo da economia do trabalho no Brasil. Além da apresentação da literatura, são destacados os temas, discussões e artigos mais relevantes. A discussão apresentada sugere uma reflexão de um ponto de vista lógico, que discute os efeitos de fatores mais amplos que os observáveis por modelos na noção de causalidade usual dos trabalhos. A conclusão apresentada é que existem muitas fragilidades anteriores aos temas convencionais que necessitam ser explicitadas, em particular, o que é nãoobservável sobre o trabalho.
\end{abstract}

Palavras-chave: Economia do trabalho; Empirismo; Brasil

\begin{abstract}
This article aims to show a literature review over the period 2007-2016 in the labor economics field of study in Brazil. In addition, topics, discussions and most relevant articles are highlighted. The discussion suggests a remark from a logical point of view, discussing the effects of broader factors than the observable by models on the notion of usual causality. The conclusion drawn is that there are many weaknesses prior to conventional issues that need to be explained, in particular, which is unobservable on the labor.
\end{abstract}

Keywords: Labor economics; Empirism; Brazil

JEL: J 01; B41

\section{Introdução}

O campo da denominada economia do trabalho abrange um conjunto de temas que evidenciam a dinâmica e atualidade dos temas debatidos em sociedade, com um apelo para a utilização de instrumentos empíricos nas análises. Trata-se de um campo recente em que estatísticas e principais características ainda estão sendo delineadas, assim como a afirmação de diretrizes metodológicas que convergem até mesmo entre correntes divergentes. Este artigo tem como objetivo comentar parte do que é produzido academicamente no período 2007-2016 no Brasil, com destaque para uma reflexão sobre a forma como é conduzida a prática acadêmica e intuito de

\footnotetext{
* Universidade Federal Fluminense
} 
apontar direcionamentos para uma economia do trabalho que debata problemas evitados não só neste campo, mas em boa parte da economia.

Essa reflexão se apresenta em um nível conceitual além do empírico. O teor de uma crítica trans-empírica refere-se a um problema de causalidade comum aos excessos da utilização de um método empírico, o dedutivismo. Todos os trabalhos analisados do artigo que se utilizam de econometria são dedutivistas, isto é, não assumem a presença de mecanismos causais não observáveis que possuem efeitos tanto em suas variáveis explicadas quanto nas explicativas.

Este artigo está subdividido em três seções, além desta introdução. Na próxima seção, discute-se a literatura da economia do trabalho no período 2007-2016, com destaque para as principais contribuições e temas mais amplamente discutidos. $\mathrm{Na}$ terceira seção, é apresentada a crítica da utilização de causalidade dedutivista sem as relativas ponderações. Por fim, na última seção, são apresentadas considerações finais sobre o trabalho.

\section{A revisão de literatura}

Os 51 identificados foram divididos em dez temas. A tabela 1 apresenta a frequência e a classificação de cada um dos temas. O tema observado com maior proporção é a "desigualdade de renda", principalmente sua relação com o crescimento econômico e sua dimensão socioeconômica. Boa parte dessa agenda se utiliza de informações da PNAD para corroborar, predominantemente, os efeitos positivos da redução da desigualdade no crescimento econômico, ou justificar a desigualdade a partir do mérito individual da qualificação nos ganhos salariais.

Tabela 1 - Temas de artigos identificados e suas respectivas proporções na amostra

\begin{tabular}{c|cc}
\hline Tema & Ocorrências & $\begin{array}{c}\text { Porcentagem } \\
\text { do total }\end{array}$ \\
\hline Desigualdade de renda & 9 & $17.65 \%$ \\
Desemprego e reinserção & 7 & $13.73 \%$ \\
ocupacional & 7 & $13.73 \%$ \\
Diferenças salariais & 6 & $11.76 \%$ \\
Capital humano & 5 & $9.80 \%$ \\
Gênero & 5 & $9.80 \%$ \\
Trabalho formal & 3 & $5.88 \%$ \\
Mobilidade & 3 & $5.88 \%$ \\
Produtividade do trabalho & 3 & $5.88 \%$ \\
Salário mínimo & 3 & $5.88 \%$ \\
Transferências de Renda & & \\
\hline
\end{tabular}

Tabela 1. Elaboração própria. 
A desigualdade de renda é o tema mais amplamente discutido na seleção, em particular o seu vínculo com o crescimento econômico. Alguns trabalhos se propõem a ser mais críticos com a visão da desigualdade puramente da renda, como Méndez e Waltenberg (2016) que abordam a desigualdade sob a perspectiva da percepção do indivíduo do que é a desigualdade e quão grande ela é percebida dependendo das posições socioeconômicas do indivíduo. Essa questão da percepção também é explorada por Rocha e Urani (2007), com enfoque no conhecimento/ desconhecimento da desigualdade. Dedecca (2012) contrasta a visão da desigualdade unidimensional da renda, uma vez que a desigualdade é um fenômeno complexo que depende de uma ampla gama de fatores sociais, incluindo o acesso aos serviços públicos de qualidade.

A temática do capital humano recorre predominantemente aos efeitos da qualificação nos rendimentos dos trabalhadores (Musse e Machado, 2013; Curi e Menezes-Filho, 2009). Cangussu, Salvato e Nakahashi (2010) inclui essa questão e vai além, posicionando o capital humano como determinante do PIB per capita. Os artigos da temática da produtividade do trabalho também se conectam à temática do capital humano, como Barbosa Filho, Pessôa e Veloso (2010) que observam no aumento da oferta de capital humano a queda na remuneração do trabalhador.

No tema do desemprego e da reinserção ocupacional, boa parte dos trabalhos se ocupou em analisar o fenômeno da informalidade em torno do período do plano real (Reis e Camargo, 2007; Scorzafave e Menezes-Filho, 2007; Silva e Gomes, 2009, Ramos, 2009). Mattos e Lima (2015) é um trabalho que em particular se preocupa com o debate sobre o desemprego no período recente, com ênfase na atual questão da existência de um pleno emprego no período recente. Seus resultados apontam que não houve pleno emprego no Brasil durante o período de 2003 a 2013.

As transferências de renda, tema que não se apresenta tão aquecido quanto no começo do século XXI, são geralmente analisadas sob a ótica dos efeitos das transferências sobre a oferta de trabalho (Cavalcanti e Correa, 2010; MARINHO e MENDES, 2013). Foguel e Barros (2010) abordam os mesmos efeitos contemplando os impactos de diferenças de gênero, indicando a existência de diferenças no impacto de programas de transferência entre homens e mulheres. Gênero é um tema que aparece em emergência na seleção dos artigos, em particular discutindo os desafios da mulher em dividir o tempo entre trabalhar e cuidar do lar (Queiroz e Aragón, 2015; Madalozzo e Gomes, 2012). Fontoura et. al. (2010) é um texto seminal na discussão de gênero ao incorporar a perspectiva social da mulher no Brasil na discussão do tempo do trabalho. Os trabalhos empíricos de gênero refletiram diferenças estatisticamente significativas entre homens e mulheres, principalmente quando se diz respeito aos rendimentos.

As diferenças salariais é um tema que se toma relevante pela necessidade de explicar ou evidenciar as diferenças de rendimentos entre grupos ou tipos de trabalhadores. Em particular, a diferença salarial entre funcionários públicos e privados (Moriconi et al., 2009; Emilio, Ponczek e Botelho, 2012; Souza e Medeiros, 2013). Outras diferenças de rendimentos entre grupos, como a dos salários entre trabalhadores de 
firmas grandes e pequenas (Menezes e Raposo, 2014), e dos trabalhadores de baixa e elevada qualificação (Silva-Jr, 2011; Pecora e Menezes-Filho, 2014), são identificadas na literatura. Menezes e Monte (2013) em particular se diferencia da análise convencional da diferença de rendimentos, e apresenta um diferencial do esforço com base no vínculo contratual do trabalhador. Diferenças salariais entre regiões são comentadas no tema "mobilidade" em Lameira, Gonçalves e Freguglia (2014), que destacam a importância das redes e da escala urbana no processo de mobilidade laboral. Monsueto, Bichara e Cunha (2014) comentam que a mobilidade ocupacional contribui para o aumento das diferenças salariais entre as regiões.

Outro tema também correlato às diferenças salariais é o trabalho formal, uma vez que a abordagem comparativa entre trabalhador formal e informal é usual. Entretanto, dos trabalhos identificados em tal tema, a discussão sobre o crescimento ou não da formalidade aparece com maior relevância. Cardoso Júnior (2009), por exemplo, se dedica a apresentar os fatores que explicam o crescimento do emprego formal, como gastos sociais, crédito interno e fiscalização do trabalho. Ulyssea (2008) também observa os aspectos positivos da fiscalização, mas aponta a possibilidade de aumento da taxa de desemprego com a fiscalização. Proni (2013) é um trabalho singular que observa no problema da informalidade a vulnerabilidade do trabalhador, e que boa parte dessa informalidade pode ser explicada por uma "cultura da informalidade" existente no Brasil, em que os esforços da política devem recair sobre. O salário mínimo, tema com poucos artigos identificados, possui um trabalho em particular intimamente conectado com o tema do trabalho formal (MEDEIROS, 2015), em que é discutido os efeitos do salário mínimo sobre o aumento da formalidade. No quadro 1 podem ser observados os artigos identificados na literatura, assim como seus respectivos dados utilizados (caso sejam trabalhos empíricos), suas premissas ou objetivos iniciais e as principais conclusões sugeridas pelos autores. 
Quadro 1. Revisão de Literatura sobre o trabalho no Brasil do período (2007-2016), artigos selecionados.

\begin{tabular}{|c|c|c|c|c|}
\hline Tema & Artigo & $\begin{array}{l}\text { Pesquisa } \\
\text { utilizada e } \\
\text { período de } \\
\text { abrangência }\end{array}$ & Premissa ou objetivo inicial & Principais conclusões sugeridas pelos autores \\
\hline \multirow[t]{6}{*}{$\begin{array}{l}\text { Capital } \\
\text { Humano }\end{array}$} & $\begin{array}{l}\text { Cangussu, } \\
\text { Salvato e } \\
\text { Nakabashi } \\
(2010)\end{array}$ & $\begin{array}{l}\text { IPEA (Dados } \\
\text { secundários) } \\
\text { (1980-2002) }\end{array}$ & $\begin{array}{l}\text { Capital humano como } \\
\text { determinante do PIB per } \\
\text { capita }\end{array}$ & $\begin{array}{l}\text { (1) Retorno marginal de um ano de escolaridade é de } 15 \% \text {; (2) } \\
\text { capital humano é significativo em todos os modelos estimados }\end{array}$ \\
\hline & $\begin{array}{l}\text { Oliveira e } \\
\text { Rios-Neto } \\
\text { (2007) }\end{array}$ & $\begin{array}{l}\text { Pesquisa } \\
\text { experimental } \\
\text { própria (1996- } \\
2000)\end{array}$ & $\begin{array}{l}\text { Efeitos do Plano Estadual } \\
\text { de Qualificação Profissional } \\
\text { (PEQ) sobre o nível de } \\
\text { desemprego de seus } \\
\text { participantes }\end{array}$ & $\begin{array}{l}\text { (1) Em geral, o impacto do programa é positivo para a } \\
\text { amostra; (2) condição de desemprego no momento de } \\
\text { treinamento afeta o grau de desfavorecimento no mercado de } \\
\text { trabalho. }\end{array}$ \\
\hline & $\begin{array}{l}\text { Musse e } \\
\text { Machado } \\
\text { (2013) }\end{array}$ & PNAD (2007) & $\begin{array}{l}\text { Análise dos impactos da } \\
\text { qualificação sobre os } \\
\text { salários }\end{array}$ & $\begin{array}{l}\text { (1) os inativos são os que mais procuram qualificação; (2) os } \\
\text { ocupados que cursam educação profissional apresentam } \\
\text { acréscimo no rendimento do mercado de trabalho }\end{array}$ \\
\hline & $\begin{array}{l}\text { Curi e } \\
\text { Menezes- } \\
\text { Filho (2009) }\end{array}$ & $\begin{array}{l}\text { PPV (1996- } \\
\text { 1997) e SAEB } \\
\text { (2003) }\end{array}$ & $\begin{array}{l}\text { Relação entre educação } \\
\text { pré-primária e os salários, } \\
\text { escolaridade e proficiência } \\
\text { escolar }\end{array}$ & $\begin{array}{l}\text { (1) pré-escola apresenta relação positiva e significante com a } \\
\text { conclusão dos quatro ciclos escolares; (2) a creche possui } \\
\text { relação positiva e significante apenas com a conclusão do } \\
\text { ensino médio e universitário; (3) a pré-escola está associada } \\
\text { com um aumento de um ano e meio de escolaridade e de } 16 \% \\
\text { na renda; (4) alunos que frequentaram a pré escola possuem } \\
\text { desempenho escolar superior das } 4^{a} \text { até a } 8^{a} \text { séries e na } 3^{a} \\
\text { série do ensino médio }\end{array}$ \\
\hline & $\begin{array}{l}\text { Tavares e } \\
\text { Menezes- } \\
\text { Filho (2011) }\end{array}$ & $\begin{array}{l}\text { PNAD (1995- } \\
\text { 2009) }\end{array}$ & $\begin{array}{l}\text { Relação entre desigualdade } \\
\text { salarial ea contribuição do } \\
\text { capital humano }\end{array}$ & $\begin{array}{l}\text { (1) a queda nos diferenciais salariais e a redução da dispersão } \\
\text { nos grupos demográficos são os responsáveis pela queda da } \\
\text { desigualdade no Brasil; ( } 2 \text { ) em geral, a educação tem um } \\
\text { impacto positivo na redução da desigualdade }\end{array}$ \\
\hline & $\begin{array}{l}\text { Silva e Neto } \\
\text { (2015) }\end{array}$ & PNAD (2008) & $\begin{array}{l}\text { Análise dos efeitos de } \\
\text { incentivos do mercado de } \\
\text { trabalho para as escolhas } \\
\text { de carreiras na } \\
\text { Universidade Federal de } \\
\text { Pernambuco }\end{array}$ & $\begin{array}{l}\text { (1) as escolhas dos candidatos são afetadas positivamente } \\
\text { pelos níveis de rendimento e pela participação das carreiras no } \\
\text { emprego total de nível superior; (2) são afetadas } \\
\text { negativamente pelo desvio-padrão dos rendimentos }\end{array}$ \\
\hline
\end{tabular}




\begin{tabular}{|c|c|c|c|c|}
\hline Tema & Artigo & $\begin{array}{l}\text { Pesquisa } \\
\text { utilizada e } \\
\text { período de } \\
\text { abrangência }\end{array}$ & Premissa ou objetivo inicial & Principais conclusões sugeridas pelos autores \\
\hline \multirow[t]{5}{*}{$\begin{array}{l}\text { Desemprego e } \\
\text { reinserção } \\
\text { ocupacional }\end{array}$} & $\begin{array}{l}\text { Monte, } \\
\text { Araújo } \\
\text { Juniore } \\
\text { Pereira } \\
\text { (2009) }\end{array}$ & PME (2000) & $\begin{array}{l}\text { Análise da influência do } \\
\text { tempo de desemprego na } \\
\text { reinserção ocupacional }\end{array}$ & $\begin{array}{l}\text { (1) evidências de chances heterogêneas de permanência no } \\
\text { estado de desemprego, quase sempre em favor dos indivíduos } \\
\text { menos qualificados, inclusive nas perdas salariais; (2) os } \\
\text { indivíduos com segundo grau ou nível superior de } \\
\text { escolaridade são os mais penalizados }\end{array}$ \\
\hline & $\begin{array}{l}\text { Scorzafave e } \\
\text { Menezes- } \\
\text { Filho (2007) }\end{array}$ & $\begin{array}{l}\text { PNAD (1981- } \\
\text { 2003) }\end{array}$ & $\begin{array}{l}\text { Análise da polarização do } \\
\text { trabalho entre domicílios } \\
\text { no Brasil }\end{array}$ & $\begin{array}{l}\text { (1) a polarização do trabalho é menor que nos países } \\
\text { desenvolvidos; (2) há um crescimento da polarização no } \\
\text { período, decorrente do aumento da fração de domicílios em } \\
\text { que os dois adultos presentes não trabalhavam }\end{array}$ \\
\hline & $\begin{array}{l}\text { Camargo e } \\
\text { Reis (2008) }\end{array}$ & $\begin{array}{l}\text { PNAD (1981- } \\
\text { 1999) }\end{array}$ & $\begin{array}{l}\text { Efeitos da renda decorrente } \\
\text { da aposentadoria sobre o } \\
\text { salário de reserva do } \\
\text { trabalhador }\end{array}$ & $\begin{array}{l}\text { (1) a maior renda decorrente da aposentadoria aumentou o } \\
\text { salário de reserva dos trabalhadores, ainda que os benefícios } \\
\text { fossem recebidos por outros membros do domicílio que não os } \\
\text { participantes da PEA; (2) o salário de reserva elevado gerou } \\
\text { um aumento de pressão salarial, levando a maiores taxas de } \\
\text { desemprego, assim como maior incidência dele no longo } \\
\text { prazo; (3) em síntese, maiores rendas de aposentadorias } \\
\text { refletem em maiores taxas de desemprego }\end{array}$ \\
\hline & $\begin{array}{l}\text { Reis e } \\
\text { Camargo } \\
(2007)\end{array}$ & $\begin{array}{l}\text { PNAD (1981- } \\
\text { 2002) }\end{array}$ & $\begin{array}{l}\text { Efeitos do plano real sobre } \\
\text { a taxa de desemprego dos } \\
\text { jovens }\end{array}$ & $\begin{array}{l}\text { (1) a rigidez salarial provocada pela redução da inflação e o } \\
\text { grau de incerteza dos empregadores sobre a produtividade do } \\
\text { trabalhador explicam o aumento da taxa de desemprego dos } \\
\text { jovens }\end{array}$ \\
\hline & $\begin{array}{l}\text { Silva e } \\
\text { Gomes } \\
\text { (2009) }\end{array}$ & $\begin{array}{l}\text { SEADE (1985- } \\
2008)\end{array}$ & $\begin{array}{l}\text { Análise do grau de } \\
\text { persistência do desemprego } \\
\text { de diferentes estratos da } \\
\text { força de trabalho na Região } \\
\text { Metropolitana de São Paulo }\end{array}$ & $\begin{array}{l}\text { (1) as políticas econômicas de combate à inflação das últimas } \\
\text { duas décadas, assim como a mudança em variáveis reais, têm } \\
\text { gerado efeitos duradouros sobre a taxa de desemprego em São } \\
\text { Paulo }\end{array}$ \\
\hline
\end{tabular}




\begin{tabular}{|c|c|c|c|c|}
\hline Tema & Artigo & $\begin{array}{l}\text { Pesquisa } \\
\text { utilizada e } \\
\text { período de } \\
\text { abrangência }\end{array}$ & Premissa ou objetivo inicial & Principais conclusões sugeridas pelos autores \\
\hline & $\begin{array}{l}\text { Ramos } \\
(2009)\end{array}$ & $\begin{array}{l}\text { PNAD (1992- } \\
\text { 2005) }\end{array}$ & $\begin{array}{l}\text { Análise do comportamento } \\
\text { do mercado de trabalho }\end{array}$ & $\begin{array}{l}\text { (1) observa-se na década de } 90 \text { um crescimento da ocupação, } \\
\text { com estagnação no segmento industrial, aumento da } \\
\text { informalidade e dos rendimentos com deterioração do } \\
\text { mercado de trabalho após o plano real; ( } 2 \text { ) nos anos } 2000 \text {, } \\
\text { observa-se maior geração líquida de postos de trabalho, } \\
\text { redução da informalidade e recuperacão dos rendimentos, o } \\
\text { reaquecimento do mercado de trabalho }\end{array}$ \\
\hline & $\begin{array}{l}\text { Mattos e } \\
\text { Lima (2015) }\end{array}$ & $\begin{array}{l}\text { PME (2003- } \\
\text { 2013) }\end{array}$ & $\begin{array}{l}\text { Existência de pleno } \\
\text { emprego no Brasil }\end{array}$ & $\begin{array}{l}\text { (1) a economia brasileira não conseguiu atingir o pleno } \\
\text { emprego ao final do período analisado, devido a persistência } \\
\text { de parcela expressiva de mão de obra subutilizada no mercado } \\
\text { de trabalho. }\end{array}$ \\
\hline \multirow[t]{4}{*}{$\begin{array}{l}\text { Desigualdade } \\
\text { de renda }\end{array}$} & $\begin{array}{l}\text { Cruz, } \\
\text { Texeira e } \\
\text { Monte-Mor } \\
\text { (2015) }\end{array}$ & $\begin{array}{l}\text { Múltiplas } \\
\text { (1995-2009) }\end{array}$ & $\begin{array}{l}\text { A redução da desigualdade } \\
\text { afeta positivamente o } \\
\text { crescimento }\end{array}$ & $\begin{array}{l}\text { (1) corrobora-se a hipótese para o Brasil, ressaltando a } \\
\text { utilização de um modelo mais completo que o utilizado na } \\
\text { literatura. }\end{array}$ \\
\hline & $\begin{array}{l}\text { Dedecca } \\
(2012)\end{array}$ & - & $\begin{array}{l}\text { Distinção entre } \\
\text { desigualdade } \\
\text { unidimensional da renda e } \\
\text { desigualdade } \\
\text { socioeconômica } \\
\text { multidimensional }\end{array}$ & $\begin{array}{l}\text { (1) sugere o enfoque de análise além da distribuição de renda } \\
\text { oriunda do mercado, isto é, além do trabalho, previdência e } \\
\text { transferências públicas, em um aspecto multidimensional. }\end{array}$ \\
\hline & $\begin{array}{l}\text { Dill e } \\
\text { Gonçalves } \\
\text { (2013) }\end{array}$ & PNAD (2009) & $\begin{array}{l}\text { Presença de serviços } \\
\text { básicos ao indivíduo é } \\
\text { definido como acesso à } \\
\text { oportunidade e são } \\
\text { influenciadas pelas } \\
\text { características do indivíduo } \\
\text { (sexo, raça, gênero, renda, } \\
\text { educação, etc.) }\end{array}$ & $\begin{array}{l}\text { (1) os resultados denotam grande disparidade no acesso à } \\
\text { oportunidade nos estados brasileiros, principalmente no } \\
\text { saneamento básico. (2) Políticas para redução da desigualdade } \\
\text { de oportunidades devem focar em saneamento pois é o serviço } \\
\text { mais precário. }\end{array}$ \\
\hline & $\begin{array}{l}\text { Manso, } \\
\text { Barreto e de } \\
\text { França } \\
(2010)\end{array}$ & $\begin{array}{l}\text { PNAD (1995- } \\
\text { 2006) }\end{array}$ & $\begin{array}{l}\text { Efeitos de políticas com } \\
\text { base no crescimento "pró- } \\
\text { pobre", com redução de } \\
\text { desigualdade de renda e } \\
\text { impacto no bem-estar }\end{array}$ & $\begin{array}{l}\text { (1) os maiores impactos na renda do trabalho devem-se à baixa } \\
\text { participação de trabalhadores por família e (2) aos ganhos de } \\
\text { produtividade a partir de 2003, motivados pelo crescimento } \\
\text { do retorno da educação. }\end{array}$ \\
\hline
\end{tabular}




\begin{tabular}{|c|c|c|c|c|}
\hline Tema & Artigo & $\begin{array}{l}\text { Pesquisa } \\
\text { utilizada e } \\
\text { período de } \\
\text { abrangência }\end{array}$ & Premissa ou objetivo inicial & Principais conclusões sugeridas pelos autores \\
\hline & $\begin{array}{l}\text { Méndez e } \\
\text { Waltenberg } \\
\text { (2016) }\end{array}$ & $\begin{array}{l}\text { Pesquisa } \\
\text { experimental } \\
\text { própria (2012) }\end{array}$ & $\begin{array}{l}\text { Efeitos da mobilidade } \\
\text { econômica subjetiva na } \\
\text { aversão à desigualdade e na } \\
\text { demanda por redistribuição } \\
\text { dos brasileiros }\end{array}$ & $\begin{array}{l}\text { (1) pessoas que aspiram ascender socialmente no futuro } \\
\text { incomodam-se com a desigualdade e são favoráveis às } \\
\text { políticas redistributivas; (2) pessoas que perceberam piora na } \\
\text { situacão econômica pessoal se mostraram favoráveis às } \\
\text { políticas redistributivas. }\end{array}$ \\
\hline & $\begin{array}{l}\text { Reis e } \\
\text { Ramos } \\
(2011)\end{array}$ & PNAD (1996) & $\begin{array}{l}\text { Relação entre rendimentos } \\
\text { e escolaridade dos pais }\end{array}$ & $\begin{array}{l}\text { (1) a estrutura educacional da família se apresenta como } \\
\text { importante determinante da desigualdade nos rendimentos do } \\
\text { trabalho; (2) a média dos rendimentos do trabalho seria maior } \\
\text { se todos os trabalhadores possuíssem os mesmos retornos à } \\
\text { escolaridade que aqueles com mães escolarizadas, enquanto a } \\
\text { desigualdade dos rendimentos reduziria ligeiramente; (3) a } \\
\text { melhoria da quantidade e qualidade da educação daqueles } \\
\text { cujos pais e mães possuem baixo nível educacional deve ser } \\
\text { uma prioridade de políticas públicas de redução da } \\
\text { desigualdade }\end{array}$ \\
\hline & $\begin{array}{l}\text { Rocha e } \\
\text { Urani } \\
\text { (2007) }\end{array}$ & ISSP (1999) & $\begin{array}{l}\text { Análise da percepção da } \\
\text { escala social e da } \\
\text { distribuição de renda }\end{array}$ & $\begin{array}{l}\text { (1) os brasileiros parecem desconhecer como a renda é de fato } \\
\text { distribuída no país; (2) esse desconhecimento envolve também } \\
\text { a magnitude da pobreza e da própria desigualdade de renda }\end{array}$ \\
\hline & $\begin{array}{l}\text { Santos e } \\
\text { Souza } \\
(2007)\end{array}$ & $\begin{array}{l}\text { RAIS (1990- } \\
\text { 1998) }\end{array}$ & $\begin{array}{l}\text { Análise do comportamento } \\
\text { dinâmico de trabalhadores } \\
\text { homens em idade produtiva }\end{array}$ & $\begin{array}{l}\text { (1) a magnitude relativa do componente de instabilidade dos } \\
\text { ganhos é muito menor que os componentes característicos } \\
\text { individuais; (2) a heterogeneidade observada, como } \\
\text { apresentadas pela educação e idade, explica somente uma } \\
\text { pequena parcela da desigualdade derivada de características } \\
\text { individuais }\end{array}$ \\
\hline & $\begin{array}{l}\text { Carvalho, de } \\
\text { Siqueira e } \\
\text { Nogueira } \\
\text { (2013) }\end{array}$ & $\begin{array}{l}\text { POF (2008- } \\
\text { 2009) }\end{array}$ & $\begin{array}{l}\text { Avaliação dos impactos da } \\
\text { carga tributária sobreo } \\
\text { bem-estar das famílias }\end{array}$ & $\begin{array}{l}\text { (1) reforma tributária de alíquotas uniformes possui impacto } \\
\text { regressivo sobre o bem-estar das famílias, enquanto as } \\
\text { baseadas nas características distributivas são progressivas. }\end{array}$ \\
\hline $\begin{array}{l}\text { Diferenças } \\
\text { salariais }\end{array}$ & $\begin{array}{l}\text { Emilio, } \\
\text { Ponczek e } \\
\text { Botelho } \\
(2012)\end{array}$ & $\begin{array}{l}\text { PME (2002- } \\
\text { 2004) }\end{array}$ & $\begin{array}{l}\text { Existência de diferenciais } \\
\text { salariais entre setor público } \\
\text { e setor privado no Brasil }\end{array}$ & $\begin{array}{l}\text { (1) os resultados não indicam grande diferença salarial entre } \\
\text { setor público e setor privado no Brasil. }\end{array}$ \\
\hline
\end{tabular}




\begin{tabular}{|c|c|c|c|c|}
\hline Tema & Artigo & $\begin{array}{l}\text { Pesquisa } \\
\text { utilizada e } \\
\text { período de } \\
\text { abrangência }\end{array}$ & Premissa ou objetivo inicial & Principais conclusões sugeridas pelos autores \\
\hline & $\begin{array}{l}\text { Menezes e } \\
\text { Raposo } \\
\text { (2014) }\end{array}$ & $\begin{array}{l}\text { PME (2006- } \\
\text { 2007) }\end{array}$ & $\begin{array}{l}\text { Relação entre salários e } \\
\text { tamanho da firma }\end{array}$ & $\begin{array}{l}\text { (1) Empresas de grande porte pagam prêmio salarial maior ao } \\
\text { esforço despendido, comparativamente às pequenas empresas; } \\
\text { (2) existe uma relação positiva entre salário e esforço laboral e } \\
\text { (3) também entre escolaridade e duração no posto de trabalho }\end{array}$ \\
\hline & $\begin{array}{l}\text { Moriconi et. } \\
\text { al. (2009) }\end{array}$ & $\begin{array}{l}\text { PNAD (1995- } \\
\text { 2004) }\end{array}$ & $\begin{array}{l}\text { Análise das diferenças } \\
\text { salarias entre setor público } \\
\text { e privado nas regiões } \\
\text { brasileiras }\end{array}$ & $\begin{array}{l}\text { (1) políticas salariais de um grande número de estados se } \\
\text { apresentou eficiente; (2) boa parte do Norte e Nordeste vêm } \\
\text { desenvolvendo políticas salariais compensatórias }\end{array}$ \\
\hline & $\begin{array}{l}\text { Pecora e } \\
\text { Menezes- } \\
\text { Filho (2014) }\end{array}$ & $\begin{array}{l}\text { PNAD (1992- } \\
\text { 2009) }\end{array}$ & $\begin{array}{l}\text { Análise do impacto da } \\
\text { oferta e demanda por } \\
\text { trabalho qualificado sobre o } \\
\text { diferencial de salários entre } \\
\text { trabalhadores de elevada e } \\
\text { baixa qualificação }\end{array}$ & $\begin{array}{l}\text { (1) elevação do diferencial salarial entre o trabalho de } \\
\text { qualificação elevada e o de baixa, impulsionado pela oferta de } \\
\text { trabalho qualificado; (2) no período } 2002-2009 \text {, percebe-se } \\
\text { uma diminuição no diferencial salarial, devido ao aumento da } \\
\text { oferta relativa de trabalho qualificado }\end{array}$ \\
\hline & $\begin{array}{l}\text { Silva-Jr } \\
\text { (2011) }\end{array}$ & $\begin{array}{l}\text { PIA e RAIS } \\
\text { (1998-2005) }\end{array}$ & $\begin{array}{l}\text { Efeitos da estrutura de } \\
\text { mercado sobre os salários } \\
\text { na indústria brasileira de } \\
\text { transformação }\end{array}$ & $\begin{array}{l}\text { (1) trabalhadores altamente qualificados apresentam ganhos } \\
\text { maiores; (2) o prêmio de qualificação se acentua pela } \\
\text { participação de mercado; 3) após a desvalorização monetária } \\
\text { de 2002, o prêmio de qualificação se apresenta maior mesmo } \\
\text { em firmas com ampla participação de mercado }\end{array}$ \\
\hline & $\begin{array}{l}\text { Souza e } \\
\text { Medeiros } \\
\text { (2013) }\end{array}$ & PNAD (2009) & $\begin{array}{l}\text { Análise da contribuição } \\
\text { específica do diferencial } \\
\text { salarial entre trabalhadores } \\
\text { com características } \\
\text { semelhantes dos setores } \\
\text { público e privado para a } \\
\text { desigualdade de renda } \\
\text { domiciliar per capita no } \\
\text { Brasil }\end{array}$ & $\begin{array}{l}\text { (1) o diferencial salarial equivale a } 17 \% \text { da massa salarial dos } \\
\text { servidores públicos, é regressivo e altamente concentrado, mas } \\
\text { tem volume pequeno na renda total (1\%) e, por isso, contribui } \\
\text { para cerca de } 3 \% \text { da desigualdade total; (2) Os efeitos sobre a } \\
\text { desigualdade da composição da força de trabalho nos setores } \\
\text { são muito maiores que efeitos da segmentação do mercado de } \\
\text { trabalho entre os dois setores }\end{array}$ \\
\hline & $\begin{array}{l}\text { Menezes e } \\
\text { Monte } \\
\text { (2013) }\end{array}$ & $\begin{array}{l}\text { PME (2006- } \\
\text { 2007) }\end{array}$ & $\begin{array}{l}\text { Relação entre } \\
\text { dedicação/ esforço do } \\
\text { trabalhador no emprego e } \\
\text { vínculo contratual }\end{array}$ & $\begin{array}{l}\text { (1) a disposição do trabalhador se altera de acordo com sua } \\
\text { dedicação, de forma que trabalhadores temporários não } \\
\text { costumam disponibilizar horas extras de trabalho e têm } \\
\text { chances maiores de serem sub-remunerados }\end{array}$ \\
\hline
\end{tabular}




\begin{tabular}{|c|c|c|c|c|}
\hline Tema & Artigo & $\begin{array}{l}\text { Pesquisa } \\
\text { utilizada e } \\
\text { período de } \\
\text { abrangência }\end{array}$ & Premissa ou objetivo inicial & Principais conclusões sugeridas pelos autores \\
\hline \multirow[t]{5}{*}{ Gênero } & $\begin{array}{l}\text { Fontoura et. } \\
\text { al. (2010) }\end{array}$ & - & $\begin{array}{l}\text { A dimensão do tempo da } \\
\text { mulher ao conciliar } \\
\text { trabalho, família e vida } \\
\text { pessoal }\end{array}$ & $\begin{array}{l}\text { (1) as políticas públicas devem contemplar a dimensão do } \\
\text { suporte às famílias, em singular no esforço de modificar os } \\
\text { estigmas tradicionais de gênero e da divisão sexual do } \\
\text { trabalho. }\end{array}$ \\
\hline & $\begin{array}{l}\text { Machado e } \\
\text { da Silva } \\
\text { (2014) }\end{array}$ & $\begin{array}{l}\text { PME (2002- } \\
\text { 2007) }\end{array}$ & $\begin{array}{l}\text { Satisfação como fator de } \\
\text { análise do mercado de } \\
\text { trabalho e diferenças de } \\
\text { satisfação entre homens e } \\
\text { mulheres }\end{array}$ & $\begin{array}{l}\text { (1) homens possuem uma probabilidade maior de estarem } \\
\text { insatisfeitos com sua ocupação que as mulheres; ( } 2 \text { ) } \\
\text { trabalhadores de atividades mais informais são os que mais } \\
\text { procuram uma nova ocupação. }\end{array}$ \\
\hline & $\begin{array}{l}\text { Madalozzo e } \\
\text { Gomes } \\
(2012)\end{array}$ & $\begin{array}{l}\text { Censo IBGE } \\
(2000)\end{array}$ & $\begin{array}{l}\text { Diferenciais salariais entre } \\
\text { mulheres casadas, solteiras } \\
\text { e em união estável }\end{array}$ & $\begin{array}{l}\text { (1) os salários diferem em até 15\% entre mulheres casadas e } \\
\text { solteiras e em até 3\% entre mulheres casadas e em união } \\
\text { estável. }\end{array}$ \\
\hline & $\begin{array}{l}\text { Simão e } \\
\text { Monsueto } \\
\text { (2008) }\end{array}$ & $\begin{array}{l}\text { PNAD (1992- } \\
\text { 2001) }\end{array}$ & $\begin{array}{l}\text { Análise dos efeitos da } \\
\text { discriminação de gênero na } \\
\text { pobreza }\end{array}$ & $\begin{array}{l}\text { (1) quando a discriminação de gênero é eliminada, a } \\
\text { porcentagem de pessoas pobres tende a se reduzir em uma } \\
\text { média de } 10 \% \text {; (2) políticas de combate à pobreza devem } \\
\text { contemplar a dimensão de gênero }\end{array}$ \\
\hline & $\begin{array}{l}\text { Queiroz e } \\
\text { Aragón } \\
\text { (2015) }\end{array}$ & PNAD (2011) & $\begin{array}{l}\text { Análise da alocação de } \\
\text { horas de trabalho pelas } \\
\text { mulheres brasileiras }\end{array}$ & $\begin{array}{l}\text { (1) o ciclo de vida, como casamento, maternidade e construção } \\
\text { da família reduzem a oferta de trabalho das mulheres; (2) a } \\
\text { educação, condição de chefe da família e acesso a creches } \\
\text { contribuem para inserção feminina no mercado de trabalho; } \\
\text { (3) a renda do esposo apresenta efeito negativo sobre a decisão } \\
\text { de trabalho da mulher }\end{array}$ \\
\hline \multirow[t]{2}{*}{ Mobilidade } & $\begin{array}{l}\text { Figueiredo } \\
\text { (2010) }\end{array}$ & $\begin{array}{l}\text { PNAD (1995- } \\
\text { 2005) }\end{array}$ & $\begin{array}{l}\text { Verificação do grau de } \\
\text { mobilidade da renda no } \\
\text { Brasil entre as gerações }\end{array}$ & $\begin{array}{l}\text { (1) o Brasil apresenta baixa mobilidade intergeracional de } \\
\text { renda, indicando estrutura social rígida; (2) A renda atual do } \\
\text { indivíduo é o principal fator determinante da sua renda futura; } \\
\text { (3) Não existe uma diferença regional expressiva nos } \\
\text { resultados. }\end{array}$ \\
\hline & $\begin{array}{l}\text { Lameira, } \\
\text { Gonçalves e } \\
\text { Freguglia } \\
\text { (2014) }\end{array}$ & $\begin{array}{l}\text { RAIS-Migra } \\
\text { (2003-2008) }\end{array}$ & $\begin{array}{l}\text { Efeitos de redes sobre a } \\
\text { mobilidade de } \\
\text { trabalhadores de curta e } \\
\text { longa distância }\end{array}$ & $\begin{array}{l}\text { (1) redes possuem efeitos significativos sobre a mobilidade } \\
\text { laboral; (2) o trabalhador se desloca para destinos com maior } \\
\text { densidade populacional, alta proporção de graduados, alta } \\
\text { atração relativa, baixa criminalidade e baixo número de } \\
\text { veículos por habitantes. }\end{array}$ \\
\hline
\end{tabular}




\begin{tabular}{|c|c|c|c|c|}
\hline Tema & Artigo & $\begin{array}{l}\text { Pesquisa } \\
\text { utilizada e } \\
\text { período de } \\
\text { abrangência }\end{array}$ & Premissa ou objetivo inicial & Principais conclusões sugeridas pelos autores \\
\hline & $\begin{array}{l}\text { Monsueto, } \\
\text { Bichara e } \\
\text { Cunha } \\
(2014)\end{array}$ & $\begin{array}{l}\text { PME (2002- } \\
\text { 2010) }\end{array}$ & $\begin{array}{l}\text { Análise dos fatores e efeitos } \\
\text { distributivos da mobilidade } \\
\text { ocupacional no Brasil }\end{array}$ & $\begin{array}{l}\text { (1) a mobilidade tem sido utilizada como via para aumento } \\
\text { salarial, inclusive quando se apresenta uma queda do status } \\
\text { sócio-ocupacional; (2) o ganho salarial ao trocar de emprego } \\
\text { ou de segmento ocupacional é diferente entre ricos e pobres, e } \\
\text { pior para os pobres; (3) a mobilidade contribui para o } \\
\text { aumento das receitas, mas também para o aumento das } \\
\text { diferenças salariais }\end{array}$ \\
\hline \multirow[t]{3}{*}{$\begin{array}{l}\text { Produtividade } \\
\text { do trabalho }\end{array}$} & $\begin{array}{l}\text { Bar*bosa } \\
\text { Filho e } \\
\text { Pessoa } \\
(2015)\end{array}$ & $\begin{array}{l}\text { PNAD e PME } \\
\text { (1982-2012) }\end{array}$ & $\begin{array}{l}\text { Redução da jornada de } \\
\text { trabalho afeta } \\
\text { negativamente a } \\
\text { produtividade }\end{array}$ & $\begin{array}{l}\text { (1) ao longo de todo o período em estudo observa-se redução } \\
\text { da jornada de trabalho. Portanto, os estudos que empregam a } \\
\text { população ocupada como medida de emprego do fator } \\
\text { trabalho superestimam a queda da produtividade }\end{array}$ \\
\hline & $\begin{array}{l}\text { Galeano e } \\
\text { Feijó (2013) }\end{array}$ & $\begin{array}{l}\text { PIA (1996- } \\
\text { 2007) }\end{array}$ & $\begin{array}{l}\text { Efeitos do crescimento } \\
\text { estrutural sobre o } \\
\text { crescimento da } \\
\text { produtividade }\end{array}$ & $\begin{array}{l}\text { (1) o crescimento da produtividade nos setores e regiões se } \\
\text { deve mais à competitividade regional que a mudanças na } \\
\text { estrutura produtiva; (2) o crescimento das regiões menos } \\
\text { desenvolvidas foi insuficiente para compensar o decréscimo na } \\
\text { região Sudeste, não havendo incremento na produtividade ao } \\
\text { nível nacional. }\end{array}$ \\
\hline & $\begin{array}{l}\text { Barbosa } \\
\text { Filho, } \\
\text { Pessôa e } \\
\text { Veloso } \\
(2010)\end{array}$ & $\begin{array}{l}\text { PNAD (1992- } \\
\text { 2007) }\end{array}$ & $\begin{array}{l}\text { Capital humano } \\
\text { determinado pela } \\
\text { produtividade marginal }\end{array}$ & $\begin{array}{l}\text { (1) construção de um índice de capital humano para o Brasil; } \\
\text { (2) o capital humano da força de trabalho no Brasil manteve- } \\
\text { se virtualmente estacionário; (3) aumento da oferta de } \\
\text { trabalho qualificado explica a queda da remuneração do } \\
\text { capital humano }\end{array}$ \\
\hline \multirow[t]{2}{*}{$\begin{array}{l}\text { Salário } \\
\text { mínimo }\end{array}$} & $\begin{array}{l}\text { Bacha e } \\
\text { Hoffmann } \\
\text { (2015) }\end{array}$ & $\begin{array}{l}\text { PNAD (2011- } \\
2012)\end{array}$ & $\begin{array}{l}\text { Variação do salário } \\
\text { mínimo causa um gap } \\
\text { entre as variações da renda } \\
\text { da PNAD e as do consumo } \\
\text { das famílias nas contas } \\
\text { nacionais }\end{array}$ & $\begin{array}{l}\text { (1) sempre que o salário mínimo crescer em termos reais mais } \\
\text { do que } 3,8 \% \text { a.a., a taxa de crescimento da renda das famílias } \\
\text { na PNAD será maior do que a taxa de crescimento do consumo } \\
\text { das famílias nas contas nacionais. }\end{array}$ \\
\hline & $\begin{array}{l}\text { Medeiros } \\
\text { (2015) }\end{array}$ & $\begin{array}{l}\text { Múltiplas } \\
(2002-2011)\end{array}$ & $\begin{array}{l}\text { Conexões entre aumento do } \\
\text { assalariamento formal e } \\
\text { elevação do poder de } \\
\text { compra do salário mínimo } \\
\text { na primeira década do séc. } \\
\text { XXI }\end{array}$ & $\begin{array}{l}\text { (1) a elevação do poder de compra do salário mínimo exerce } \\
\text { influência positiva sobre a taxa de salário de trabalhadores } \\
\text { formais e informais; (2) contribuiu para elevação do emprego } \\
\text { formal e redução da pobreza. }\end{array}$ \\
\hline
\end{tabular}




\begin{tabular}{|c|c|c|c|c|}
\hline Tema & Artigo & $\begin{array}{l}\text { Pesquisa } \\
\text { utilizada e } \\
\text { período de } \\
\text { abrangência }\end{array}$ & Premissa ou objetivo inicial & Principais conclusões sugeridas pelos autores \\
\hline & $\begin{array}{l}\text { Menezes- } \\
\text { Filho e } \\
\text { Rodrigues } \\
\text { (2009) }\end{array}$ & $\begin{array}{l}\text { PNAD (1981, } \\
\text { 1988, 1989) }\end{array}$ & $\begin{array}{l}\text { Análise do efeito do salário } \\
\text { mínimo sobre a } \\
\text { distribuição salarial }\end{array}$ & $\begin{array}{l}\text { (1) a queda do salário mínimo real ao longo do período explica } \\
\text { boa parte do aumento da dispersão salarial; ( } 2 \text { ) a evolução do } \\
\text { salário mínimo, da composição da educação, grau de } \\
\text { sindicalização e características individuais exercem influência } \\
\text { no aumento da desigualdade salarial ao longo do período } \\
\text { estudado }\end{array}$ \\
\hline \multirow[t]{4}{*}{$\begin{array}{l}\text { Trabalho } \\
\text { formal }\end{array}$} & $\begin{array}{l}\text { Cardoso } \\
\text { J únior } \\
\text { (2009) }\end{array}$ & $\begin{array}{l}\text { PNAD (1995- } \\
\text { 2005) }\end{array}$ & $\begin{array}{l}\text { Regulação e políticas } \\
\text { públicas como fatores } \\
\text { historicamente impactantes } \\
\text { do emprego formal }\end{array}$ & $\begin{array}{l}\text { (1) o crescimento do emprego formal no período é explicado } \\
\text { por cinco fatores: gastos sociais, crédito interno, saldo } \\
\text { exportador, regime tributário simplificado para empresas de } \\
\text { pequeno porte e fiscalização das relações de trabalho; (2) há } \\
\text { espaço para políticas públicas pois o Estado possui capacidade } \\
\text { de controlar boa parte de tais fatores }\end{array}$ \\
\hline & $\begin{array}{l}\text { Corseuil, } \\
\text { Reis e Brito } \\
(2014)\end{array}$ & $\begin{array}{l}\text { PNAD (2009- } \\
\text { 2011) }\end{array}$ & $\begin{array}{l}\text { Distintos critérios de } \\
\text { definição do trabalho } \\
\text { informal impactam no } \\
\text { diagnóstico da formalidade } \\
\text { einformalidade no Brasil } \\
\end{array}$ & $\begin{array}{l}\text { (1) as características dos trabalhadores formais e informais são } \\
\text { sensíveis ao critério de informalidade; (2) discussões de } \\
\text { políticas públicas devem ter seus objetivos de acordo com a } \\
\text { definição de informalidade utilizada. }\end{array}$ \\
\hline & $\begin{array}{l}\text { Corseuil, } \\
\text { Foguel } \\
\text { (2012) }\end{array}$ & $\begin{array}{l}\text { PME (2003- } \\
\text { 2008) }\end{array}$ & $\begin{array}{l}\text { A parcela do emprego } \\
\text { formal cresce à medida que } \\
\text { a taxa de desemprego cai e } \\
\text { o hiato salarial entre } \\
\text { empregados formais e } \\
\text { informais aumenta }\end{array}$ & $\begin{array}{l}\text { (1) os dados da PME corroboram a hipótese de que no período } \\
\text { de crescimento da economia brasileira, tanto a taxa de } \\
\text { desemprego cai quanto o hiato salarial entre empregados } \\
\text { formais e informais aumenta }\end{array}$ \\
\hline & Proni (2013) & $\begin{array}{l}\text { PNAD (2003, } \\
2008,2009)\end{array}$ & $\begin{array}{l}\text { Análise da vulnerabilidade } \\
\text { ocupacional no Brasil }\end{array}$ & $\begin{array}{l}\text { (1) o crescimento econômico deve ser acompanhado de } \\
\text { medidas sustentáveis e eficientes que reduzam a } \\
\text { vulnerabilidade do trabalhador, principalmente diante do } \\
\text { diagnóstico de que há uma cultura da informalidade no Brasil }\end{array}$ \\
\hline
\end{tabular}




\begin{tabular}{|c|c|c|c|c|}
\hline \multirow[t]{2}{*}{ Tema } & Artigo & $\begin{array}{l}\text { Pesquisa } \\
\text { utilizada e } \\
\text { período de } \\
\text { abrangência }\end{array}$ & Premissa ou objetivo inicial & Principais conclusões sugeridas pelos autores \\
\hline & $\begin{array}{l}\text { Ulyssea } \\
\text { (2008) }\end{array}$ & PNAD (2003) & $\begin{array}{l}\text { Análise dos aspectos } \\
\text { institucionais relativos à } \\
\text { informalidade no mercado } \\
\text { de trabalho }\end{array}$ & $\begin{array}{l}\text { (1) elevações no seguro-desemprego e reduções no imposto } \\
\text { sobre a folha de geram impactos positivos, porém reduzidos, } \\
\text { sobre os indicadores do mercado de trabalho; (2) uma } \\
\text { intensificação da fiscalização governamental leva a } \\
\text { significativas reduções da informalidade, mas também } \\
\text { provoca uma elevação substancial da taxa de desemprego e } \\
\text { uma piora em outros indicadores do mercado de trabalho } \\
\text { brasileiro }\end{array}$ \\
\hline \multirow[t]{3}{*}{$\begin{array}{l}\text { Transferências } \\
\text { de renda }\end{array}$} & $\begin{array}{l}\text { Cavalcanti e } \\
\text { Corrêa } \\
(2010)\end{array}$ & - & $\begin{array}{l}\text { Modelo endógeno de busca } \\
\text { de emprego (com impacto } \\
\text { da transferência de renda) }\end{array}$ & $\begin{array}{l}\text { (1) a dimensão da renda transferida tem efeito negativo sobre } \\
\text { a taxa de emprego e um efeito ambíguo sobre a taxa de } \\
\text { desemprego; (2) a cobertura do programa de transferência de } \\
\text { renda tem efeito positivo sobre a taxa de emprego e efeito } \\
\text { ambíguo sobre a taxa de desemprego }\end{array}$ \\
\hline & $\begin{array}{l}\text { Marinho e } \\
\text { Mendes } \\
\text { (2013) }\end{array}$ & PNAD (2006) & $\begin{array}{l}\text { Impacto das transferências } \\
\text { de renda do Governo sobre } \\
\text { a oferta de trabalho formal } \\
\text { einformal dos chefes de } \\
\text { família no Brasil }\end{array}$ & $\begin{array}{l}\text { (1) as transferências de renda do Governo contribuíram para o } \\
\text { aumento da probabilidade de o pai de família estar } \\
\text { desempregado e trabalhando no setor informal. }\end{array}$ \\
\hline & $\begin{array}{l}\text { Foguel e } \\
\text { Barros } \\
(2010)\end{array}$ & $\begin{array}{l}\text { PNAD (2001- } \\
\text { 2005) }\end{array}$ & $\begin{array}{l}\text { Diferenças de gênero no } \\
\text { impacto dos Programas } \\
\text { Condicionais de } \\
\text { Transferência de Renda } \\
\text { (PCTR) sobre a oferta de } \\
\text { trabalho. }\end{array}$ & $\begin{array}{l}\text { (1) os resultados indicam que o impacto do PCTR sobre a } \\
\text { oferta de trabalho feminino não é significante } \\
\text { estatisticamente, enquanto para os homens o efeito é positivo, } \\
\text { mas de pequena magnitude; (2) os resultados corroboram o } \\
\text { argumento de que o PCTR não impacta o mercado de trabalho. }\end{array}$ \\
\hline
\end{tabular}

Fonte: Elaboração Própria. 


\section{Novas direções para a economia do trabalho}

Existe uma questão lógica - atualmente em emergência no debate da filosofia da ciência- que pode ser definido pelo uso indiscriminado de conjunções constantes de eventos como uma condição de causalidade. De acordo com Lawson (1997), tal problema lógico é definido como dedutivismo. Uma afirmação dedutivista é aquela que define uma relação da forma "se x ocorre, então y ocorre", ou basicamente "x causa y". A econometria instrumentaliza tal lógica, e todo e qualquer trabalho empírico identificado na revisão aqui apresentada se adequa a essa forma. Por exemplo, em Cangussu, Salvato e Nakabashi (2010), "capital humano causa PIB per capita", ou em Menezes e Raposo (2014), "tamanho da firma causa salários".

Certamente, esse exercício ignora as demais variáveis utilizadas e o modelo, os controles, os métodos de estimação, assim como determinadas ponderações feitas pelos autores. De qualquer forma, seus resultados sugerem a interpretação da causalidade dedutivista de seus modelos estimados. Mas será que essas conjunções constantes de eventos são causadas, em última instância, pelo x? Para explicar esse problema, será apresentado aqui um exercício ilustrativo.

A ilustração do problema é um experimento do alto de um prédio, no qual o cientista testa os efeitos de exercer diferentes forças sobre um objeto ao lançá-lo ao solo, com interesse em explicar o tempo com que o objeto chega ao solo. Primeiro, lança ao solo exercendo força mínima, e sucessivamente vai exercendo força maior, à medida que observa também que o tempo de chegada ao solo diminui. O modelo do cientista então revela que "a força exercida causa diminuição no tempo de chegada", de forma negativa, quanto maior a força ao lançar o objeto ao solo, menor o tempo de chegada. Seu modelo econométrico satisfez a todos os critérios empíricos, mas éuma causalidade empírica incompleta. Longe deacreditar quea força do cientista não tem efeito no modelo, ele negligencia um mecanismo que exerce efeito sobre ele e o ambiente, a gravidade. A gravidade não pode ser modelada por esse cientista pois ele não a observa, a gravidade é um mecanismo não empírico, isto é, trans-empírico. É impossível se observar a gravidade, exceto pelos seus efeitos. Os efeitos da gravidade são observáveis, mas podem nos enganar, pois seus efeitos só se manifestam quando o cientista exerce a força, mesmo que seja mínima, para soltar o objeto de suas mãos.

A ausência de mecanismos (ou leis) trans-empíricos são uma explicação factível para, nos trabalhos empíricos aqui analisados, assumir modelos completamente diferentes para questões semelhantes, mesmo com indagações teóricas semelhantes. Carecem de leis que expliquem, em última instância, a alta conjunção constante de eventos encontrados (Lawson, 2003).

O modelo do cientista carece de uma noção de causalidade que possa ao menos reconhecer a existência de fenômenos trans-empíricos. A grandequestão é, quais são os mecanismos causais em economia? São apenas os efeitos de fenômenos observáveis ou também efeitos de mecanismos trans-empíricos? Como manejar essa questão, em particular com relação ao trabalho? 
Para exemplificar essa questão, utilizando o exemplo do gênero, recorre-se aqui ao artigo de Fontoura et. al. (2010). Por mais que trabalhos empíricos como Machado e da Silva (2014), Madalozzo e Gomes (2012) e Queiróz e Aragón (2015) revelem sim que há uma diferença salarial entre mulheres e homens, ou entre mulheres entre diferentes condições, não se explica o elemento trans-empírico que faz com que esses efeitos se concretizem. Fontoura et. al. (2010) revela que, para além de toda e qualquer correlação causal, existem estigmas reais e tradicionais do gênero na nossa sociedade. Estigmas de gênero não são compreendidos empiricamente, ao menos até então, não é possível observar ou medir estigmas sociais. E se não podemos observar ou medir, ao menos podemos observar seus efeitos, por exemplo, nas diferenças salariais. Mas deve ser imperativo que o que causa a diferença salarial é o estigma, não o fato de um ser se apresentar como mulher e o outro como homem. E o estigma, melhor reformulado aqui como "impressão que a sociedade carrega da mulher" pode ser tão alvo de políticas públicas quanto uma correção salarial, ou novos benefícios. A diferença é que, como mecanismo, a redução do estigma teria efeito sobre os fenômenos observáveis que a econometria captura bem (figura 1).

Figura 1. Esquematização de uma lógica contemplando fenômenos empíricos e trans-empíricos para o tema "gênero"

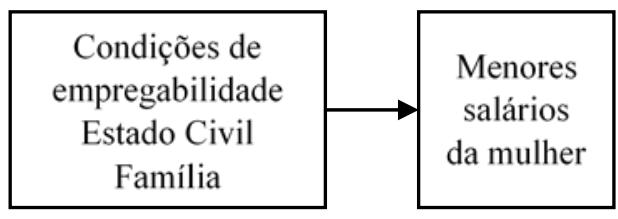

Proposição empirista

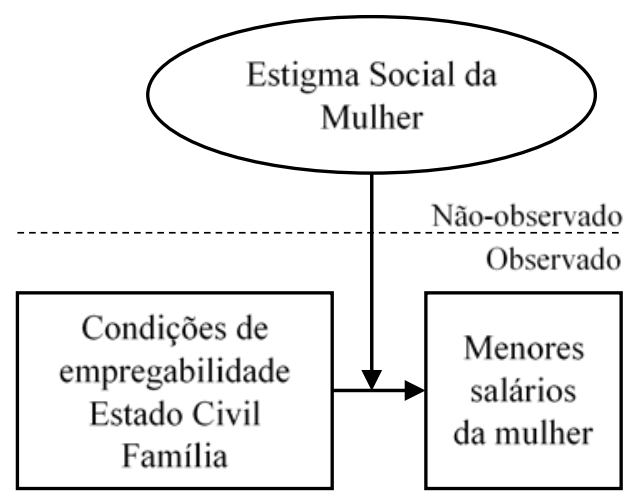

Proposição trans-empírica

Figura 1. Elaboração própria

Estes exemplos levam a uma reinterpretação em um sentido mais amplo: a proposta empirista busca uma relação de sentido único, sem qualquer adaptação interna ao sistema na forma como as variáveis observadas e não observadas se relacionam. Em grande medida, a lógica empirista se ocupa em encontrar padrões de relação para os efeitos e pouca atenção dedica à percepção e inserção social do agente gerador do fato. Em particular, nas discussões empíricas sobre mercado de trabalho, busca-se encontrar a causalidade dos fenômenos e pouco se discute quanto à percepção causada pela experiência dos fenômenos pelas instituições que atuam no sistema: empresas, trabalhadores, regras, normas e convenções. A forma como os agentes 
percebem as interações institucionais altera não apenas a forma como suas relações se formam como também a forma como as instituições se adaptam.

Ostrom (2005) chama atenção à esta decomposição de efeitos que ocorre em uma "arena de ação". Neste ambiente, as variáveis exógenas cujos efeitos são observados ou não, afetam, por um lado, a forma como os agentes interagem para gerar seus (1) "Resultados" (os efeitos observados gerados dentro do sistema, e.g. o salário da mulher), bem como estes resultados podem atuar alterando (2) os mecanismos nãoobservados ou (3) a forma como estes são percebidos na arena de ação (figura 2).

Figura 2. Esquematização da decomposição de interações institucionais

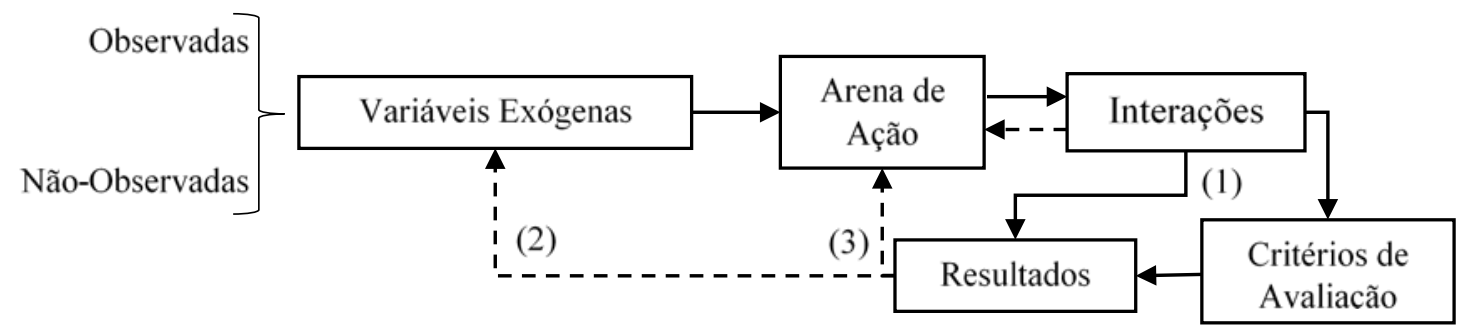

Figura 2. Adaptado de Ostrom (2005)

Diante da necessidade de estabelecer o aspecto trans-empírico na elucidação e explicação das causalidades empíricas, é necessário desenvolver os motivos da fluência no meio acadêmico de um empirismo fracamente mediado. A resposta para essa fluência, certamente, é estabelecida pela concepção de ciência que inspira a economia moderna.

A questão é que a concepção de ciência que serve às ciências naturais não pode ser irrestritamente incorporada ao campo das ciências sociais, inclusive no que diz respeito aos experimentos. Uma distinção que deve ser sempre levada em consideração pelo pesquisador é a entre um sistema fechado e um sistema aberto. Sistemas fechados são conjunções constantes de eventos restritas às condições experimentais, desenvolvidas de forma bem-sucedida nas ciências naturais. Essas são as condições de laboratório, em que cientistas conseguem controlar um fenômeno (Bhaskar, 1989; 1998).

Nas ciências sociais e, em particular, na economia, não é possível separar em experimento as formas de sociabilidade que estão intrínsecas aos problemas econômicos. Basta notar, por exemplo, os impactos das mudanças culturais do século XXI, em que os trabalhadores são dotados de forma social da necessidade de consumir bens eletrônicos. É possível perceber o efeito (aumento na demanda por bens) e seu impacto na oferta de trabalho. Sobre uma relação de oferta e demanda, que é possível de se analisar empiricamente, há o efeito de uma tendência de penetração social que deve necessariamente ser contemplada analiticamente. A 
mudança social é condição necessária para compreender um sistema observável econômico aberto - sujeito às mudanças que certamente alteram a dinâmica social. A estrutura familiar, a globalização, a questão de gênero, racial, as aspirações do trabalhador, a informalidade, e toda a dinâmica que envolvem tais temas de profunda relação com o sistema econômico.

Portanto, as proposições empíricas são capazes de propor mecanismos para coordenar problemas? Se apenas a causalidade sobre efeitos observados pode ser elucidada, então apenas soluções de contrapeso podem ser percebidas pelos modelos. Como se justificam os mecanismos incapazes de demonstrar eficácia em uma modelo que busca simular um sistema fechado? Por outro lado, a construção de um arcabouço que admite a existência de relacionamentos trans-empíricos e dos mecanismos pelos quais seus fenômenos são produzidos e podem ser adaptados, permite a proposição de soluções não-observáveis, como medidas de combate ao estigma de gênero em complemento às medidas de correções salariais.

\section{Considerações finais}

O esforço aqui apresentado fornece (1) uma apresentação de boa parte da literatura e temas recentes discutidos na área denominada economia do trabalho; (2) destaque para determinados trabalhos que apresentam direcionamentos de maior ineditismo, em particular a complexidade e multidimensionalidade das questões concernentes ao trabalho e o trabalhador; (3) conjunções empiristas foram apontadas aqui como muitas das vezes incapaz de identificar causalidades, diante dos efeitos de estruturas não-observáveis sobre o que se consegue capturar empiricamente.

O desdobramento natural desse artigo éna reflexão do que acontece no campo social que retroalimenta os resultados empíricos. Se há uma cultura de informalidade no Brasil, como tratar um problema cultural que não é observado em modelos? Seria impossível ao economista que estima modelos ao menos especular em seus trabalhos sobre fatos sociais como o racismo, a exclusão e a miséria no Brasil? E que tais fatos reais possuem efeitos sobre a realidade observável, isto é, os modelos?

O custo em elucidar uma análise empírica a partir do estudo em sistema aberto é, imperativamente, abordar a complexidade dos sistemas econômicos, conjugados em sistemas sociais. Trata-se de um projeto de ciência que efetivamente conflita com as convicções da economia moderna, mas que aborda os problemas dos quais a economia tenta se omitir. A economia do trabalho, campo da economia que possui a capacidade de revelar as efetividades de políticas para o trabalhador, é capaz de gerar reflexões teóricas que incorporem os fenômenos sociais não-observáveis melhor que qualquer outro campo.

\section{Referências}

BACHA, E. \& HOFFMANN, R. (2015), 'Statistical interpretation of the GDP, the PNAD and the minimum wage', Revista de Economia Política 35(1), 64--74.

BARBOSA FILHO, F. D. H.; PESSÔA, S. D. A. \& VELOSO, F. A. (2010), 'Evolução da produtividade total dos fatores na economia brasileira com ênfase no capital humano - 1992-2007', Revista Brasileira de Economia 64(2), 91--113. 
BARBOSA-FILHO, F. H. \& PESSÔA, S. A. (2014), 'Pessoal ocupado e jornada de trabalho: uma releitura da evolução da produtividade no Brasil', Revista Brasileira de Economia 68(2), 149-- 169.

BHASKAR, R. (1989), 'Reclaiming reality: A critical introduction to contemporary philosophy', Taylos \& Francis.

BHASKAR, R. (1998), Societies In: 'Critical Realism: Essential Readings', Routledge, pp. 206--57.

CAMARGO, J. M. \& REIS, M. C. (2008), 'Aposentadoria, pressão salarial e desemprego por nível de qualificação', Revista Brasileira de Economia 62(3), 299$-331$.

CANGUSSU, R. C.; SALVATO, M. A. \& NAKABASHI, L. (2010), 'Uma análise do capital humano sobre o nível de renda dos estados brasileiros: MRW versus Mincer', Estudos Econômicos (São Paulo) 40(1), 153--183.

CARDOSO J UNIOR, J. C. (2009), 'Determinantes da recuperação do emprego formal no Brasil: evidências para o período 2001/2005 e hipoteses para uma agenda de pesquisa', Revista de Economia Política 29(4), 357--376.

CARVALHO, D. B.; DE SIQUEIRA, R. B. \& NOGUEIRA, J. R. B. (2013), 'Características Distributivas e Impacto de Reformas Tributárias Sobre o Bem-Estar das Famílias no Brasil'(3)'Revista Brasileira de Economia', 263--282.

CAVALCANTI, T. \& CORREA, M. (2010), 'Cash Transfers and the Labor Market', Revista Brasileira de Economia 64, 175-- 190.

CORSEUIL, C. H.; REIS, M. C. \&BRITO, A. S. (2015), 'Critérios de classificação para ocupação informal: consequências para a caracterização do setor informal e para a análise de bem-estar no Brasil', Estudos Econômicos (São Paulo) 45(1), 5--31.

CORSEUIL, C. H. L. \& FOGUEL, M. N. (2012), 'Economic expansion and increase in labour market formality: a poaching approach', Revista Brasileira de Economia 66(2), 207--224.

DA CRUZ, P. B.; TEIXEIRA, A. \& MONTE-MOR, D. S. (2015), 'O Efeito Da Desigualdade Da Distribuição De Renda No Crescimento Econômico', Revista Brasileira de Economia 69(2), 163--186.

CURI, A. Z. \& MENEZES-FILHO, N. A. (2009), 'A relação entre educação préprimária, salários, escolaridade e proficiência escolar no Brasil', Estudos Econômicos (São Paulo) 39(4), 811--850.

DEDECCA, C. S. (2012), 'Desigualdade, mas de qual falamos?', Revista de Economia Política 32(1), 55-- 71.

DILL, H. C. \& GONÇALVES, F. D. O. (2013), 'Igualdade de oportunidade entre os estados brasileiros: uma análise microeconométrica com base nos dados da PNAD 2009', Nova Economia 23(2), 307--328.

EMILIO, D.; PONCZEK, V. \&BOTELHO, F. (2012), 'Evaluating the wage differential 
between public and private sectors in Brazil', Revista de Economia Política 32(1), $72--86$.

FIGUEIREDO, E. A. (2010), 'Mobilidade intergeracional de renda no brasil', Nova Economia 20(3), 427--455.

FOGUEL, M. N. \&DE BARROS, R. P. (2010), 'The effects of conditional cash transfer programmes on adult labour supply: an empirical analysis using a time-series-crosssection sample of Brazilian municipalities', Estudos Econômicos (São Paulo) 40(2), 259--293.

FONTOURA, N.; PINHEIRO, L.; GALIZA, M. \& VASCONCELOS, M. (2010), 'Pesquisas de uso do tempo no Brasil: contribuições para a formulação de políticas de conciliação entre trabalho, família e vida pessoal', Revista Econômica 12(1).

FREGUGLIA, R.; VIEIRA, M. \& MARIONI, L. (2015), Industry and Regional Wage Differentials Revisited: A Longitudinal Comparison of the Use of Alternative Sampling Approaches, in 'XIII ENCONTRO NACIONAL DA ASSOCIAÇÃO BRASILEIRA DE ESTUDOS REGIONAIS E URBANOS - Curitiba'.

GALEANO, E. \& FEIJÓ, C. (2013), 'estagnação da produtividade do trabalho na indústria brasileira nos anos 1996-2007: análise nacional, regional e setorial', Nova Economia 23(1), 9--50.

LAMEIRA, V. D. C.; GONÇALVES, E. \& FREGUGLIA, R. D. S. (2015), 'O Papel das Redes na Mobilidade Laboral de Curta e Longa Distância: Evidências para o Brasil Formal', Estudos Econômicos (São Paulo) 45(2), 401--435.

LAWSON, T. (1997), Economics and Reality, Psychology Press.

LAWSON, T. (2003), Reorienting economics, Psychology Press.

MÉNDEZ, Y. S. \& WALTENBERG, F. D. (2016), 'Aversão à desigualdade e preferências por redistribuição: a percepção de mobilidade econômica as afeta no Brasil?', Estudos Econômicos (São Paulo) 46(1), 91--125.

MACHADO, D. C. \& DA SILVA, A. F. (2014), 'Um indicador de não satisfação no trabalho e a mobilidade do mercado de trabalho: um estudo para homens e mulheres', Nova Economia 24(1), 123--140.

MADALOZZO, R. \& GOMES, C. F. (2012), 'The impact of civil status on womencs wages in Brazil', Estudos Econômicos (São Paulo) 42(3), 457--487.

MANSO, C. A.; BARRETO, F. A. F. D. \& DE FRANÇA, J. M. S. (2010), 'Bem-estar social, mercado de trabalho e o desequilíbrio regional brasileiro', Estudos Econômicos (São Paulo) 40(2), 401--443.

MARINHO, E. \& MENDES, S. (2013), 'The impact of government income transfers on the Brazilian job market', Estudos Econômicos (São Paulo) 43(1), 29--50.

MATTOS, F. A. M. \&DA SILVA LIMA, S. (2015), 'Apontamentos para o debate sobre o pleno emprego no Brasil', Economia e Sociedade 24(2), 293--328. 
MEDEIROS, C. A. (2015), 'A influência do salário mínimo sobre a taxa de salários no Brasil na última década', Economia e Sociedade 24(2), 263--292.

DE MENEZES, T. A. \& DO MONTE, P. A. (2013), 'Relação entre o tipo de contrato de trabalho e a dedicação do trabalhador no emprego: evidências para as regiões metropolitanas brasileiras', Nova Economia 23(1), 51--72.

DE MENEZES, T. A. \& RAPOSO, I. P. D. A. (2014), 'Wage differentials by firm size: the efficiency wage test in a developing country', Estudos Econômicos (São Paulo) 44(1), 45--67.

MENEZES-FILHO, N. \& RODRIGUES, E. A. D. S. (2009), 'Salário mínimo e desigualdade no Brasil entre 1981-1999: uma abordagem semiparamétrica', Revista Brasileira de Economia 63(3), 277--298.

MONSUETO, S. E.; CUNHA, A. M. \& DA SILVA BICHARA, J . (2014), 'Movilidad ocupacional y diferencial de ingresos: la experiencia del Brasil entre 2002 y 2010', Revista CEPAL.

MONSUETO, S. E. \& SIMÃO, R. C. S. (2008), 'The impact of gender discrimination on poverty in Brazil', Cepal Review.

DO MONTE, P. A.; DE ARAÚJ O J ÚNIOR, I. T. \& PEREIRA, M. D. L. (2009), 'O custo salarial da duração do desemprego para o trabalhador', Nova economia 19(3), 443--470.

MORICONI, G. M.; NETO, J. S. M.; MARCONI, N. \& ARVATE, P. R. (2009), 'Diferentes padrões de políticas salariais nos estados brasileiros: uma análise a partir do diferencial de salários público-privado.', Brazilian Journal of Political Economy/ Revista de Economia Política 29(3).

MUSSE, I. \& MACHADO, A. F. (2015), 'Perfil dos indivíduos que cursam educação profissional no Brasil', Economia e Sociedade 22(1), 237--262.

DE OLIVEIRA, A. M. H. C. \& RIOS-NETO, E. L. G. (2007), 'Uma avaliação experimental dos impactos da política de qualificação profissional no Brasil', Revista Brasileira deEconomia 61(3), 353--378.

OSTROM, E. (2005), Understanding institutional diversity, Vol. 241, Princeton University Press Princeton.

PECORA, A. R. \&MENEZES-FILHO, N. (2014), 'O papel da oferta e da demanda por qualificação na evolução do diferencial de salários por nível educacional no Brasil', Estudos Econômicos (São Paulo) 44(2), 205--240.

PRONI, M. W. (2013), 'Decent work and occupational vulnerability in Brazil', Economia e Sociedade 22(3), 825--854.

QUEIROZ, V. D. S. \& ARAGÓN, J. A. O. (2015), 'Alocação de tempo em trabalho pelas mulheres brasileiras', Estudos Econômicos (São Paulo) 45(4), 787--819.

RAMOS, L. (2009), 'Desempenho recente do mercado de trabalho brasileiro: 19922005', Revista de Economia Política 29(4), 406--420. 
REIS, M. C. \&CAMARGO, J . M. (2007), 'Desemprego dos jovens no Brasil: os efeitos da estabilização da inflação em um mercado de trabalho com escassez de informação', Revista Brasileira de Economia 61(4), 493--518.

REIS, M. C. \& RAMOS, L. (2011), 'Escolaridade dos pais, desempenho no mercado de trabalho e desigualdade de rendimentos', Revista Brasileira de Economia 65(2), 177--205.

ROCHA, R. \&URANI, A. (2007), 'Posicionamento social e a hipótese da distribuição de renda desconhecida. Brasil: quão pobres, quão ricos e quão desiguais nos percebemos', Revista de Economia Política 27, 4.

SANTOS, A. L. \& SOUZA, A. P. (2007), 'Earnings Inequality in Brazil: Is it Permanent or Transitory?', Brazilian Review of Econometrics 27(2), 259--284.

SCORZAFAVE, L. G. \& Menezes-Filho, N. A. (2007), 'Famílias com trabalho e famílias sem trabalho: evidências de polarização para o Brasil', Estudos Econômicos (São Paulo) 37(3), 563--584.

DA SILVA, C. G. \&GOMES, F. A. R. (2009), 'Measuring unemployment persistence of different labor force groups in the Greater São Paulo Metropolitan Area', Estudos Econômicos (São Paulo) 39(4), 763--784.

DA SILVA, D. F. C.; NETO, S. \& DA MOTA, R. (2015), 'Escolhas de carreiras universitárias e mercado de trabalho: Uma análise da influência dos incentivos econômicos', Nova Economia 25(3), 519--552.

SILVA-J R, G. G. (2011), 'Market structure effects on wages in the Brazilian industrial firms', Estudos Econômicos (São Paulo) 41(3), 521--536.

SOUZA, P. H. G. F. \& MEDEIROS, M. (2013), 'Diferencial salarial público-privado e desigualdade de renda per capita no Brasil', Estudos Econômicos (São Paulo) 43(1), 5--28.

TAVARES, P. A. \& MENEZES-FILHO, N. A. (2013), 'Human capital and the recent fall of earnings inequality in brazil', Rede de Economia Aplicada Working Paper 62.

ULYSSEA, G. (2008), 'Instituições e a informalidade no mencado de trabalho', Estudos Econômicos (São Paulo) 38(3), 525--556. 